\title{
Wrought Aluminium Alloy Corrosion Propensity in Domestic Food Cooking Environment
}

\author{
S. O. Adeosun, ${ }^{1}$ E. I. Akpan, ${ }^{2}$ and S. A. Balogun ${ }^{1}$ \\ ${ }^{1}$ Department of Metallurgical and Materials Engineering, University of Lagos, Lagos, Nigeria \\ ${ }^{2}$ Department of Materials and Production Engineering, Ambrose Alli University, Ekpoma, Nigeria \\ Correspondence should be addressed to E. I. Akpan, emma_eia@yahoo.com
}

Received 29 August 2012; Accepted 23 September 2012

Academic Editors: S. J. Lee and M. Sakairi

Copyright $(2012$ S. O. Adeosun et al. This is an open access article distributed under the Creative Commons Attribution License, which permits unrestricted use, distribution, and reproduction in any medium, provided the original work is properly cited.

\begin{abstract}
The study on corrosion behaviour of wrought aluminium alloy in domestic food cooking conditions has been examined using the gravimetric approach. Flat cold rolled and annealed sheets were subjected to solutions of Capsicum annuum, L. esculentum, Allium серa, and their blend under three conditions, namely, heating and cooling in still air, heating and cooling in refrigerator, and leaving some in open still atmosphere. Results show that corrosion occurred within the test period (288 hours) in the test environments. There was severe degradation within the first 70 hours of test when coupons were heated and cooled while unheated coupon showed low corrosion propensity. Microstructural analysis show the presence of corrosion pits on coupon surface with second phase particles sandwiched in $\alpha$-aluminium matrix. Immersed coupon in the blend media show higher number of pits on the surface. Rapid corrosion of wrought aluminium alloy in Capsicum annuum, L. esculentum and Allium cepa media is attributed to the presence of corrosion aggressive elements such as allicin, diallyl-disulphide, and allyl-propyl disulphide present in the corrosion media.
\end{abstract}

\section{Introduction}

Aluminium alloy cookware, containers, cooking utensil, and aluminium beverage cans contribute substantially to the consumption load of aluminium $[1,2]$. Deep drawn aluminium utensils are widely used as domestic cooking vessel in the third world countries. Such utensils are subjected to several heating cycles during their service lives. In aggressive cooking environment the aluminium is very prone to localized attack and progressive failure that occurs due to pitting which shortens the service life span of these cooking utensils $[3,4]$.

A study conducted at the University of Cincinnati Medical Centre [5] reveal that acid forming foods dissolve aluminium more rapidly and that tomatoes cooked in an aluminium pot had 2 to 4 milligram aluminium content in serving. The corrosion products particle is leached from the utensil into the foods being cooked.

It has been shown that healthy human body can handle up to twenty milligrams of aluminium ingestion per day [1], this absorbed aluminium is eliminated through the kidney in form of urine and unabsorbed aluminium is excreted in the faeces $[1,6]$. Unfortunately, the activity of the kidney decreases with age $[3,6]$. At 65 years and above, the ability of the kidney to eliminate aluminium diminishes [3], resulting in the accumulation of these particles in the body. These particles are distributed mainly in bone, liver, testes, kidneys, and brain $[1,6]$. Numerous studies have indicated that aluminium accumulates in the body, especially in nerves tissues, causing harm $[1,2,7,8]$. Scientists have established a link between aluminium and Alzheimer's diseases, the commonest cause of senile and presenile dementia, clumsiness of moments, staggering when walking, and inability to pronounce words properly [7-10]. Dementia is an ailment where the patient exhibits progressive loss of memory and other higher mental functions as a result of the brain cells and the development of plaques and tangles $[5,7,9,10]$. Behavioural difficulties among school children have been correlated with elevated levels of aluminium and other neurotoxic heavy metals [8] while the toxicity may also cause birth defects in newborns [1].

Corrosion rates can increase from a low rate to several thousand mils per year as a result of increasing temperature 


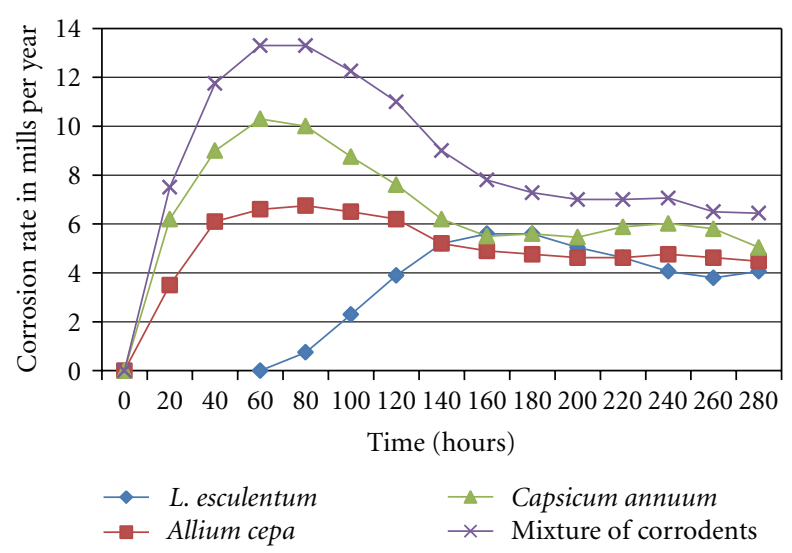

FIGURE 1: Corrosion responses of wrought aluminium alloy heated and super cooled in a refrigerator.

[11]. Microorganisms presence in the medium can influence corrosion behaviour through production of slimes and deposits which give rise to crevice corrosion and by creating corrosive conditions through their metabolic products. They may destroy materials added to the system to provide corrosion inhibition and may directly influence the corrosion reactions. The operating conditions that affect microbiologically induced corrosion (MIC) of materials include flow rate (velocity), temperature, pressure, $\mathrm{pH}$, oxygen level, cleanliness of the system, and presence of water. MIC-related bacterial growth typically occurs in systems within specific temperature ranges, depending on the bacteria [12]. The range is often reported as being between 4 and $49^{\circ} \mathrm{C}$. More than $90 \%$ of MIC is seen as pitting-type corrosion. This is due to the fact that most microbiological community usually remains fixed to the colonization site.

Aluminium is known to corrode nonuniformly because of preferential attack on grain boundaries, which results in a symptomatic feature [13]. This susceptibility of aluminium to localized corrosion makes it particularly vulnerable to MIC. There are two mechanisms for MIC that have been documented for aluminium and its alloys, namely, production of water-soluble organic acids by bacteria and fungi, and the formation of differential aeration cells [14].

Study on corrosion of deep drawn wrought and cast AA 6063 aluminium alloy in Lycopersicum esculentum (tomatoes) at a temperature other than ambient temperature has revealed that cast cylindrical utensils pit much more readily than deep drawn utensils [4]. The pits noticed in cast utensil is traceable to the presence of microcracks as a result of hydrogen embrittlement phase, precipitation of brittle second phase particles, and the fine texture in cast utensil. The study also revealed that the deformation of wrought aluminium alloy and its subsequent annealing helped to improve its corrosion resistance in L. esculentum solution during domestic heating cycles. The effect of temperature on corrosion activity of domestic aluminium cooking utensils is envisaged. Therefore this paper investigates the corrosion behaviour of wrought aluminium alloy in domestic food cooking environments at high, room, and refrigeration temperatures in the presence of three most used domestic ingredients-Capsicum annuum (pepper), L. esculentum (tomatoes), and Allium cepa (onion).

\section{Experimental Methodology}

Sheets of both cold and hot rolled annealed wrought aluminium alloys were provided by Aluminium Rolling Mills Ota, Ogun State, Nigeria for the study. Table 1 shows the composition of the aluminium alloy.

Rectangular specimens of dimension $50 \mathrm{~mm} \times 50 \mathrm{~mm} \times$ $1.2 \mathrm{~mm}$ were cut out of the circular sheets and subjected to corrosion test in $250 \mathrm{~mL}$ solutions of Capsicum annuum, $L$. esculentum, Allium cepa, and their blend in three different conditions vis-a-vis:

(1) heating in solutions for $20 \mathrm{~min}$ and supercooling in a refrigerator,

(2) heating in solutions for $20 \mathrm{~min}$ and cooling in still air,

(3) control test (keping at room temperature).

The $\mathrm{pH}$ of the solution was recorded using Jenway 350 meter and the corrosion rate was measured in mils per year using the gravimetric method. Prepared coupons were immersed in the corrosion media and the weight loss measured periodically over 288 hours at 24 hours interval. At the end of the tests, coupon surface was prepared for metallographic examination and etched using a mixture of nitric acid, hydrofluoric acid, and water for about $50 \mathrm{~s}$.

\section{Results and Discussions}

The response of wrought aluminium alloy to corrosion in solutions of Capsicum annuum, L. esculentum, Allium cepa, and their blend at different conditions are shown in Figures 1, 3, and 5. Coupons heated and supercooled in a refrigerator showed remarkably high degradation level of corrosion within 288 hours of the study (see Figure 1). Corrosion rate is highest for the specimen immersed in blend media, followed by coupon immersed in Capsicum annuиm and that immersed in Allium cepa. Coupon immersed in $L$. esculentum solution does not show significant erosion below 70 hours of test. The corrosion rate for other coupons rose steadily to a maximum $(7,10,13 \mathrm{mpy})$ value at 70 hours beyond which it declines and remains constant over the remaining period of the test. This initial rapid corrosion of the alloy in most of the media in the first seventy hours of the test can be attributed to the presence of corrosion aggressive elements in the corrosion medium (New Jersey Department of Health and Senior Services, Hazardous substances Fact sheet: Allyl Propyl Disulfide, 1994, PO Box368, Trenton NJ 08625-0368.) A. cepa contains allicin, diallyl-disulphide, and allyl-propyl disulphide. C. annuum on the other hand, has some percentage of cayenne pepper that can generate phenolic compound (capsaicin) [15], while L. esculentum contains citric, oxalic and malic acids.

In the microstructure of the second phase crystals are sandwiched in $\alpha$-aluminium matrix and in coupon immersed in heated and super-cooled solution of $C$. 


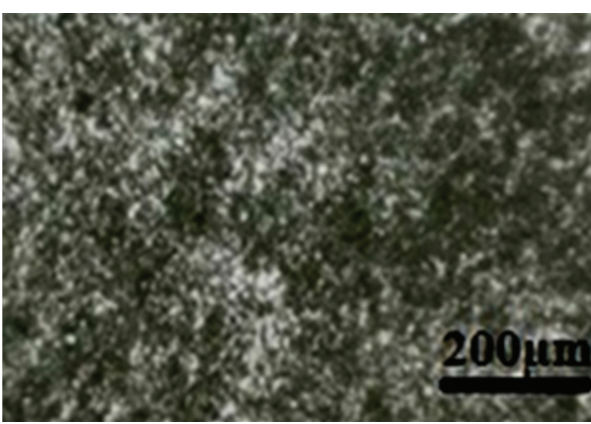

(a)

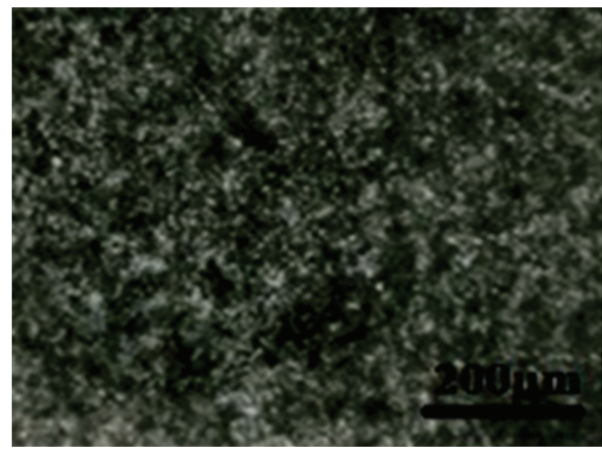

(c)

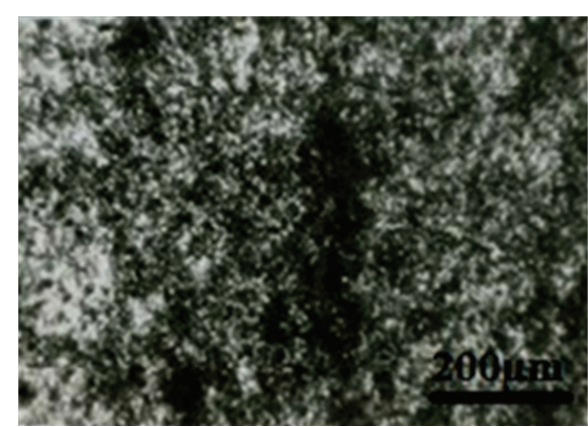

(b)

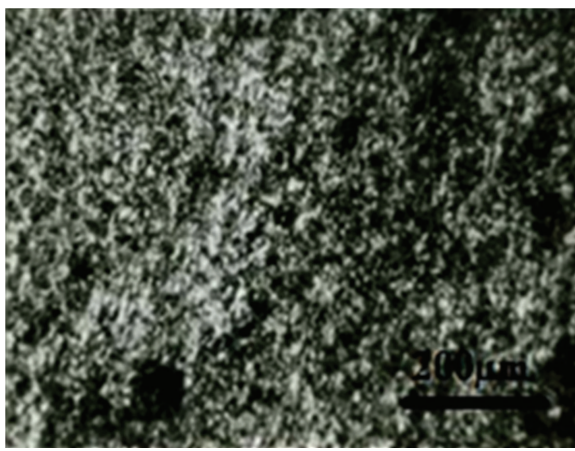

(d)

FIgURE 2: Microstructures of wrought aluminium alloy immersed in (a) C. annuum, (b) L. esculentum, (c) A. cepa, and (d) mixed media, heated, and supercooled in a refrigerator.

TABLE 1: Chemical analysis of aluminium alloy blank sheet.

\begin{tabular}{lcccccccccc}
\hline Element & $\mathrm{Al}$ & $\mathrm{Si}$ & $\mathrm{Cu}$ & $\mathrm{Mn}$ & $\mathrm{Mg}$ & $\mathrm{Zn}$ & $\mathrm{Cr}$ & $\mathrm{Ti}$ & $\mathrm{Ca}$ & $\mathrm{Sn}$ \\
\hline $\mathrm{Wt}, \%$ & 99.06 & 0.23 & 0.56 & 0.05 & $<0.001$ & 0.04 & 0.01 & 0.02 & $<0.001$ & $<0.001$ \\
\hline
\end{tabular}

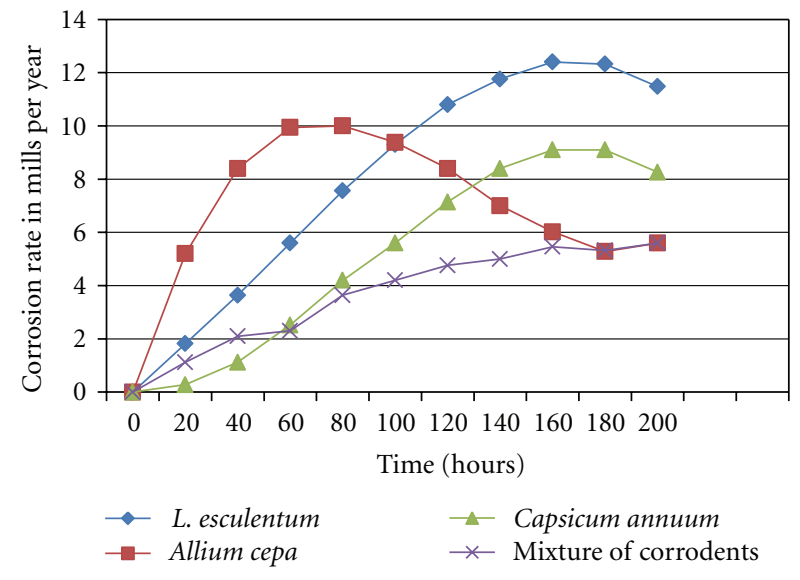

FIGURE 3: Corrosion responses of wrought aluminium alloy heated and cooled in still air.

annuum. Small-sized pits are developed and shown as dark spots and these are well distributed in the matrix (see Figure 2(a)). The coupon immersed in L. esculentum solution shows matrix with decreased volume fraction of second phase precipitates (see Figure 2(b)). The developed pits indicate growth towards each other. Coupon tested in blend solution showed morphology with (see Figure 2(d)) large-sized pits which are scattered in its matrix with considerable erosion of $\alpha$-aluminium phase crystals. However, there is high volume of the intermetallic precipitates in Figure 2(c) than that in Figure 2(d).

The cumulative corrosion rate of coupon heated and left standing in the atmosphere for 216 hours is higher (12.5 mpy) when placed in solution of L. esculentum than in any other test solution. Corrosion rates fluctuate for samples immersed in C. annuum and A. cepa solutions and a gradual decrease in the corrosion propensity is observed in the samples immersed in the blend test solution (see Figure 3). The high corrosion rate in L. esculentum solution can be attributed to its hydroxonium strength [4] nature $(\mathrm{pH}=4.40)$.

The morphology of coupon in C. annuum (see Figure 4(a)) test solution revealed similar intermetallic precipitates distribution to that of Figure 2(c) but developed pits have smaller diameter. The number of pits increased in coupons tested in L. esculentum (see Figure 4(b)) and A. cepa (see Figure 4(c)) solutions and the pits are evenly distributed in the matrices. The pits in C. annuum tested coupon are larger than those in L. esculentum coupon. 


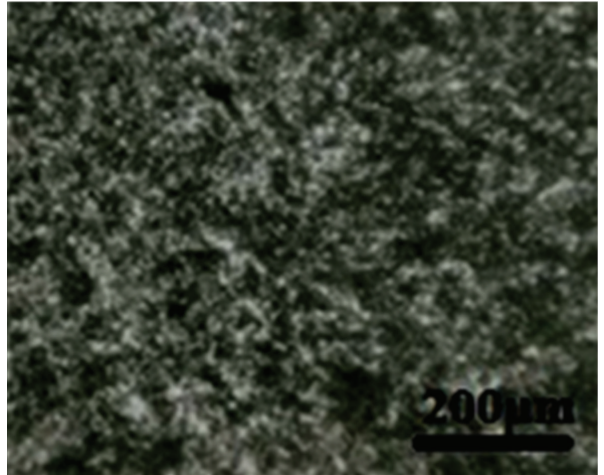

(a)

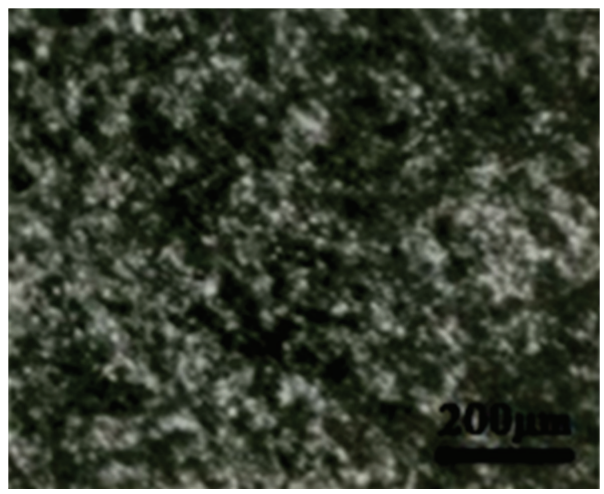

(c)

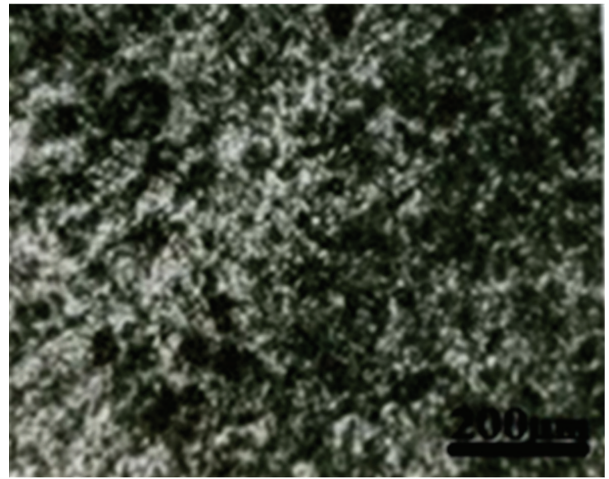

(b)

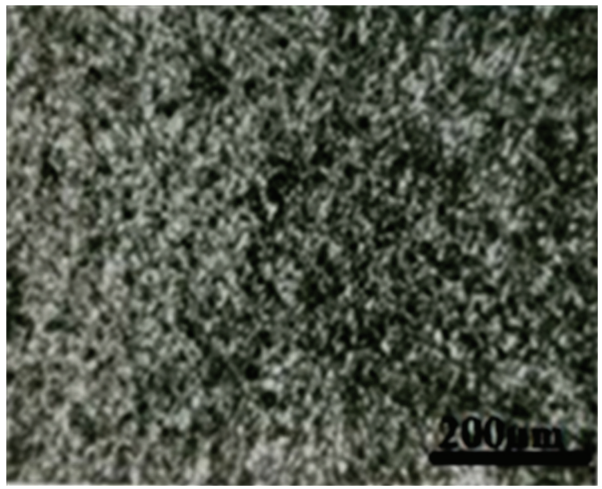

(d)

Figure 4: Microstructures of wrought aluminium alloy immersed in (a) C. annuum, (b) L. esculentum, (c) A. cepa, and (d) mixed media, heated, and aircooled.

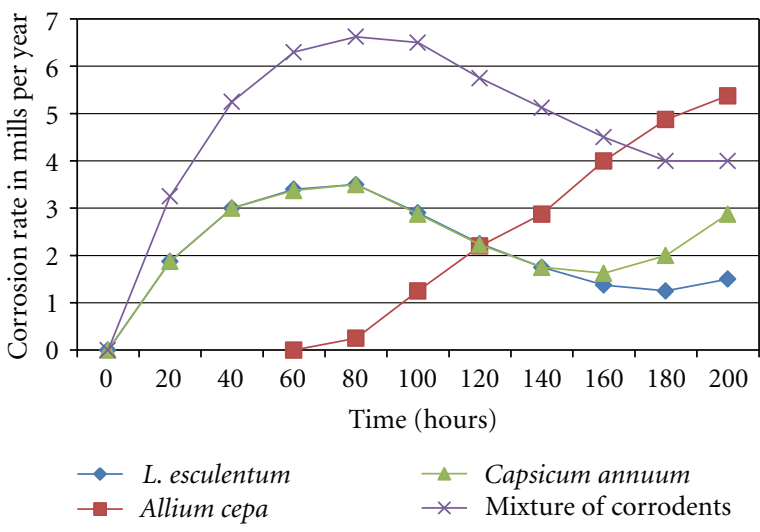

FIGURE 5: Corrosion responses of wrought aluminium alloy tested at ambient temperature.

The pits developed on coupon exposed to blend solution are relatively small and well distributed (see Figure $4(\mathrm{~d})$ ) with second phase crystals precipitate covering $\alpha$-aluminium matrix.

The corrosion rates of wrought aluminium alloy coupons immersed in corrosion test environments without heating (control specimens) show better resistance to degradation by the test media when compared to those subjected to temperature above ambient (see Figure 5). The highest corrosion rate $(7.00 \mathrm{mpy})$ occurs in coupon immersed in the blend test solutions. Coupons immersed in C. annuum and L. esculentum show similar corrosion behaviour within 160 hours of exposure. Below 70 hours coupon immersed in Allium cepa show inactivity with the test environment but this passivity breaks down after 80 hours as corrosion rate rises steadily with time. Macroscopic examination of coupons tested at ambient revealed green colouration of the surface which is an indication of the presence of algae. Thus, the corrosion behaviour of aluminium in domestic cooking solutions can be accelerated by a combination of heating and atmospheric exposure. The combined action of temperature and bacterial attacks make aluminium vulnerable to attack by solutions.

In the control coupon microstructure well-distributed pits are shown over the matrix surface with intermetallic precipitates sandwiched between $\alpha$-aluminium matrix in $C$. annuum solution (see Figure 6(a)). Sparsely dispersed pits are found in the entire matrix of L. esculentum solution tested solution (see Figure 6(b)) while $\alpha$-aluminium phase is considerably eroded. The coupon tested in $A$. cepa solution show higher number of tiny pits well distributed with uneven distribution of second phase crystals in the matrix (see Figure 6(c)). The number of the pits developed in the matrix of coupon exposed to blend solution (see Figure 6(d)) is 


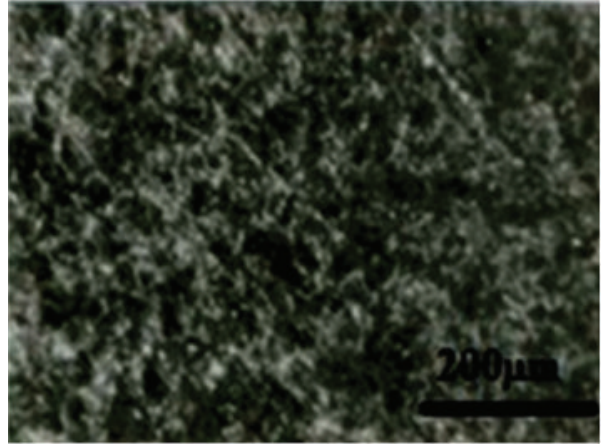

(a)

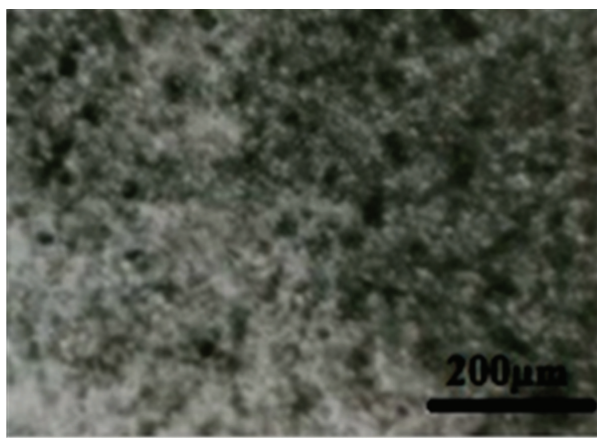

(c)

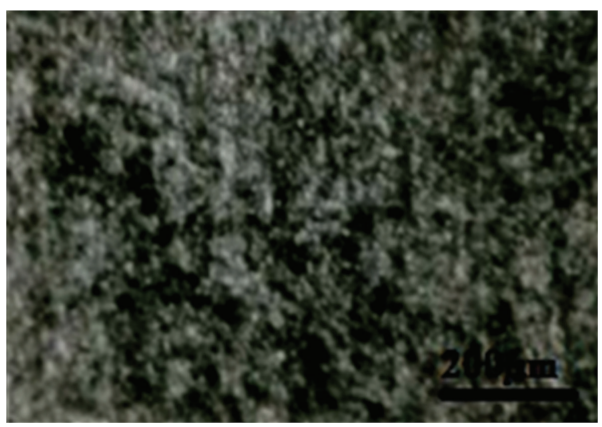

(b)

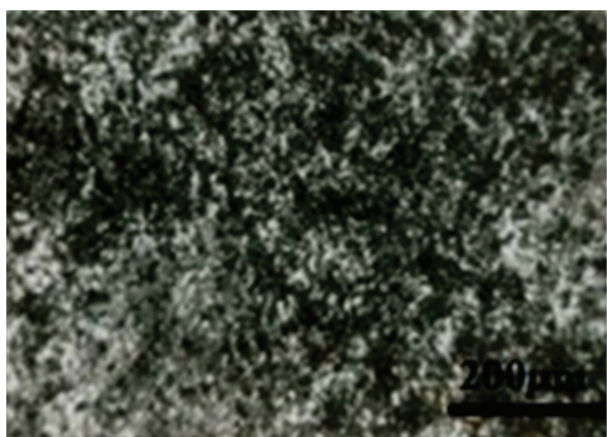

(d)

FIgURE 6: Microstructures of wrought aluminium alloy immersed in (a) C. annuum, (b) L. esculentum, (c) A. cepa, and (d) mixed media at ambient temperature.

higher than those found in coupon immersed in $A$. cepa (see Figure 6(c)).

\section{Conclusion}

Experimental investigation of the corrosion behaviour of wrought aluminium alloy in different cooking conditions showed the following.

(1) The aluminium alloy undergo some level of pitting corrosion under these cooking conditions in the presence of L. esculentum, A. серa, and C. annuum.

(2) The corrosion behaviour of aluminium in domestic cooking solutions can be accelerated through heating and by atmospheric exposure.

(3) The blend of L. esculentum, A. cepa, and C. annuum solution leads to increase corrosion rate of the domestic aluminium cooking utensils.

(4) Storing of utensils containing cooking media in a refrigerating system after heating will ensure stable state of the utensils. In freezing region, action of bacteria is hindered and electrons/ions interactions are sluggish. Consequently, there will be little or no significant reaction of the media with the metal. It may therefore, be deduced that the act of refrigerating cooked food will not only preserve the food but will also reduce the level of aluminium leaching into the food and prolong the service life of the cooking utensils.

\section{References}

[1] ATSDR (Agency for Toxic Substances and Disease Registry), "Toxicological Profile for Aluminum, Agency for Toxic Substances and Disease Registry," US Public Health Service, ATSDR/TP, 88/01, Atlanta, Ga, USA, 1990.

[2] M. R. Wills and J. Savory, "Water content of aluminum, dialysis dementia, and osteomalacia," Environmental Health Perspectives, vol. 63, pp. 141-147, 1985.

[3] Aluminium and Health, "UK Aluminium Industry Information Sheet," Information Sheet 2, 2004.

[4] S. A. Balogun, D. E. Esezobor, and S. O. Adeosun, "Stress corrosion cracking of cast 6063 and deep drawn 1017 aluminum utensils in Lycopersicum esculentum," Journal of Materials Engineering and Performance, vol. 16, no. 6, pp. 720725, 2007.

[5] C. Exley, Aluminium and Alzheimer's Disease: The Science that Describes the Link, Elsevier, Amsterdam, The Netherlands, 2001.

[6] B. Venugopal and T. O. Luckey, Metal Toxicity in Mammals, vol. 2 of Chemical Toxicity of Metals and Metalloids, Plenum Press, 1978.

[7] M. F. A. Berkum and D. R. C. McLachlan, "Aluminum: a role in degenerative brain disease associated with neurofibrillary degeneration," Progress in Brain Research, vol. 70, pp. 399-410, 1986. 
[8] R. A. Goyer, "Toxic Effects of Metals," in Casarett \& Doull's Toxicology: The Basic Science of Poisons, M. O. Amdur, J. Doull, and C. D. Klassen, Eds., pp. 622-6663, Permogen Press, 4th edition, 1991.

[9] D. Shore and R. J. Wyatt, "Aluminum and Alzheimer's disease," Journal of Nervous and Mental Disease, vol. 171, no. 9, pp. 553558, 1983.

[10] A. I. Arieff, J. D. Cooper, D. Armstrong, and V. C. Lazarowitz, "Dementia, renal failure, and brain aluminum," Annals of Internal Medicine, vol. 90, no. 5, pp. 741-747, 1979.

[11] M. G. Fontana, Corrosion Engineering, McGraw-Hill, New York, NY, USA, 3rd edition, 1986.

[12] P. Angell, "Understanding microbially influenced corrosion as biofilm-mediated changes in surface chemistry," Current Opinion in Biotechnology, vol. 10, no. 3, pp. 269-272, 1999.

[13] D. A. Jones, Principles and Prevention of Corrosion, Prentice Hall, Upper Saddle River, NJ, USA, 1996.

[14] E. Juzeliunas, R. Ramanauskas, A. Lugauskas et al., "Investigation of micro biologically influenced corrosion two-year exposure of aluminium to penicillium frequentans aspergillus niger and bacillus mycoides," CHEMIJA, vol. 16, no. 2, pp. 1217, 2005.

[15] T. Sun, Z. Xu, C. T. Wu, M. Janes, W. Prinyawiwatkul, and H. K. No, "Antioxidant activities of different colored sweet bell peppers (Capsicum annuum L.)," Journal of Food Science, vol. 72, no. 2, pp. S98-S102, 2007. 

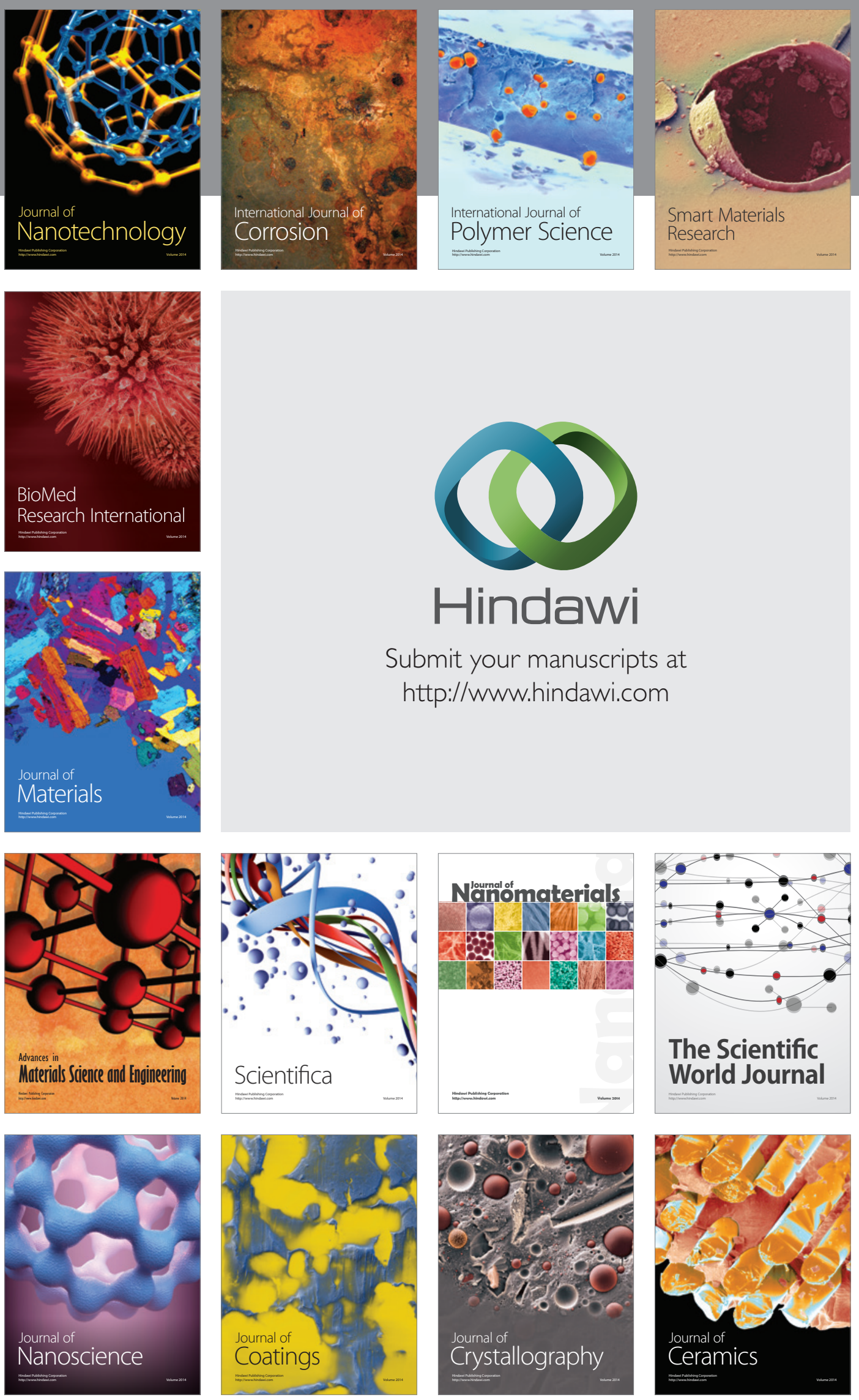

The Scientific World Journal

Submit your manuscripts at

http://www.hindawi.com

\section{World Journal}

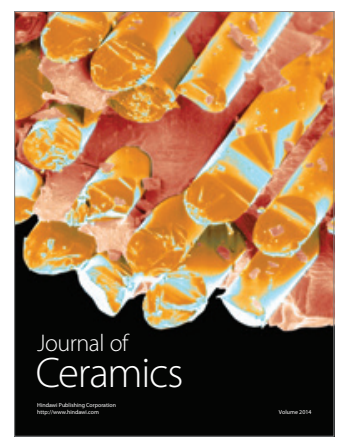

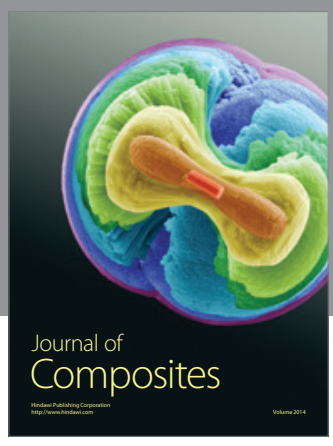
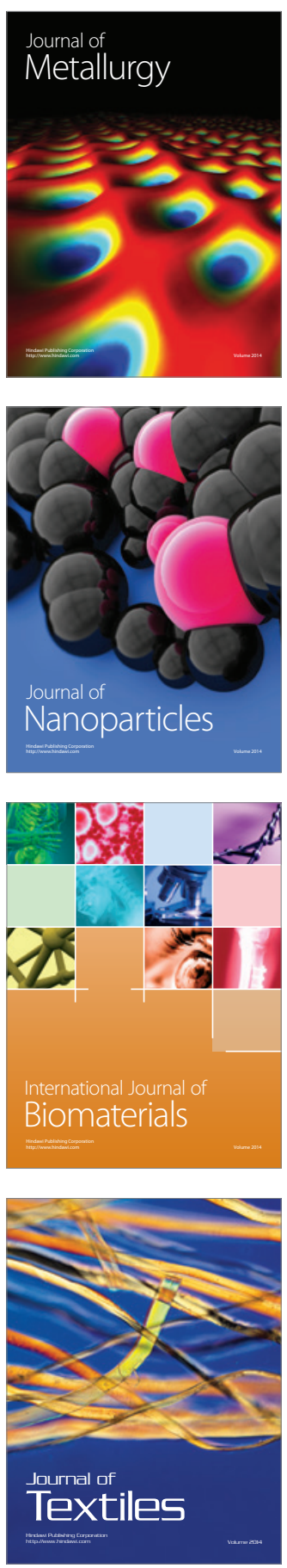